\title{
CORRIGENDUM
}

\section{Global minutes: globalization: its impact on health}

\section{Vidyasagar}

Journal of Perinatology (2006) 26, 262. doi:10.1038/sj.jp.7211418

Correction to: Journal of Perinatology 2005;25:669-670. doi:10.1038/sj.jp.7211376; published online 1 September 2005
Following the publication of the above paper, the author has identified an error in the title. The correct title is shown above. 